\title{
Ultrasonic signal processing techniques for Pipeline: A review
}

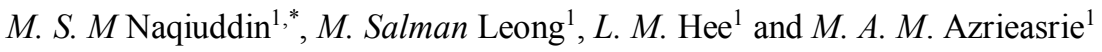 \\ ${ }^{1}$ Institute of Noise and Vibration, Universiti Teknologi Malaysia, Jalan Sultan Yahya Petra, 54100 Kuala Lumpur, Malaysia
}

\begin{abstract}
Monitoring pipeline wall is an important issue in oil and gas industries. Over time, the defect can occur in the pipeline and can impact surrounding population, environment and may result in injuries or fatalities. While flaws in the pipeline could be detected by ultrasonic testing and monitoring the severity of the flaw. The limitation of ultrasonic testing is the signal contaminate with backscattering noise, which masks flaw echoes in the measured signal. Signal processing take place in the recent year to de-noising for improving signal-to-noise ratio and extract the feature for flaws classification. This paper presents a comprehensive overview of signal processing techniques used to improve ultrasonic detection method with and without intelligent classifier. Finally, the advantages and disadvantages feature extraction provided for classifications process.
\end{abstract}

\section{Introduction}

The pipeline has been constructed to transport the gasses and liquids over a long distance from their sources to the ultimate consumer. They are an important part of our infrastructure. Over the time, the pipeline needs to inspect and monitor, some severe damage in the pipeline will heading to large catastrophic failure [1]. To overcome this problem, many techniques to monitor the integrity of pipeline such as ultrasonic. Ultrasonic testing is a power tool to inspect the pipe and the welds area [2].

Ultrasound is a high voltage pulse that generated by piezoelectric crystal in ultrasonic transducer. The ultrasound wave will propagate into the material being tested via couplant and it reflects if any discontinuity within the material such as defect. The reflected wave depends on a factor called acoustical impedance ratio. The acoustical impendence ratio between two materials is simply the acoustical impendence of one material divided by the acoustical impedance of the other material. The higher the ratio, the more of the original energy will be reflected. The few of wave will be generated in ultrasonic transducers such as longitudinal wave, shear wave, Rayleigh wave and lamb wave. The wave that reflected will produce a voltage in the receiver. Two type transducers existing which are pulseecho (same transducer transmitting and receiving) and pitch-catch configuration (separation transducer) [3].

The received signal can display in three different types which are A-scan, B-scan, and C-scan. A-scan is display based on the returned signal from the test material which function of time for the specific location. In B-scan, display a two-dimensional view of the crosssectional plane through the test object. Another common display in plan view called C-scan. The transducer is scanned the regular pattern over an area of interest then generated the output in the image. The received signal very useful information for detection and analyze the reflected by the discontinuity of material. However, the output signal may contaminate of noises during test [4]. Signal processing introduced to eliminate the noise from the measurement

Hence, the research interest towards signal processing, because signal processing have a good performance to extract feature in every measured signal that helpful in de-noising and classify the flaw in pipe. The purposes of this review paper to summarize ultrasonic signal processing techniques

This paper organized as follow: the section 2 discussed the common defect occur in the pipeline system. Section 3 and 4 discovered the existing signal processing and existing signal processing with the intelligent classifier. Finally, section 5 contains our conclusion

\section{Common defect in pipeline}

\subsection{Corrosion}

Corrosion is a common defect in material and relies on several factors such as temperature, $\mathrm{pH}$, pressure, chemical composition, the microstructure of steel and etc. When the pipeline used in operation condition, corrosion can occur internally and externally. Under certain environmental, the metal pipe can be corroded based on the pipe metal properties, the soil surrounding the pipe and fluid properties. Corrosion is a timedependent process that gradually reduces the internal and external wall [5]. In oil and gas pipeline, the presence of carbon dioxide $(\mathrm{CO} 2)$ and hydrogen sulfide $(\mathrm{H} 2 \mathrm{~S})$ can cause severe internal corrosion [6-9]. Cathodic

\footnotetext{
* Corresponding author: naqiu_salleh@yahoo.com
} 
protection is one of the techniques that can mitigate the corrosion [10].

\subsection{Crack}

Usually, the crack can occur in fabrication process or during operation. These flaws can seriously compromise the integrity of a pipeline. Crack are often invisible to the eye that can weaken a pipeline causing catastrophic failure. In the pipeline, several factors can cause cracking such as stress induced cracking [11] and hydrogen induced cracking (HIC) [12], [13]. The highstress field can cause the hydrogen accumulate without any inclusion or another interface. In the pipeline, crack occur in the base material, in welds and in the heataffected zone adjacent to welds [14], [15]. Cracks can also appear in substandard axial and girth welds.

\subsection{Porosity}

Trapped gas in weld bead commonly happen and called porosity. During welding in joining the two pipeline, the torch being applied and the gas in the molten metal released and trapped on solidification [16]. It could be wide in gas dispersion throughout the welds. It needs a proper way in welding process to avoid porosity defect. Poor porosity can cause severe in pipeline process and usually, ultrasonic testing takes part to detect the severity of porosity

\subsection{Errosion}

Erosion can be described as the mechanical loss of material by the movement of fluid or another particle on the surface of the pipe. Fluid turbulence can result the erosion [17], [18]. The oil and gas industry has suffered and continues to face many failures that can be attributed to erosion. Under turbulence operating conditions, to avoid the erosion occur in the pipeline, flow velocity and production limits are set to some limit. Erosion also caused from cavitation [19], cavitation occurs when a rapid change of pressure in the pipeline and can lead to a very severe which are grooves, valleys, wavy surface, and hole. In addition to careful design, it may be prevented through the selection of pipe material

\section{Signal Processing}

In ultrasonic non-destructive testing, the signal is very useful of information including amplitude and time delay. From ultrasonic signal, it can identify the size and depth of the flaw. Even though the accurate detection signal is challenging because the signal possibly contaminated by noise from various type of source, e.g., from the measurement system and material itself [20]. The noise from measurement simply to address because it is typically low effect to the ultrasonic signal. While material noise or structure noise is most serious and high scattering signal during the testing of coarse-grained. Each grain structure behaves like a center of scattering, and the resulting noise is therefore correlated to the input signal. For example, when the grain size is similar to the size of the defect, the defect echo will mask by structure noise and the output signal may make the detection of small flaw difficult, and the greatly limits the accuracy of flaw detection methods. The received signal can be defined in form $x(t)=a(t)+n_{1}(t)+n_{2}(t)$ where $a(t)$ is ultrasonic flaw echo, $n_{1}(t)$ is backscattering noise and $n_{2}(t)$ is caused from electronic circuitry noise [21-22]. In figure 1 the biggest grain size will cause the high backscattering signal

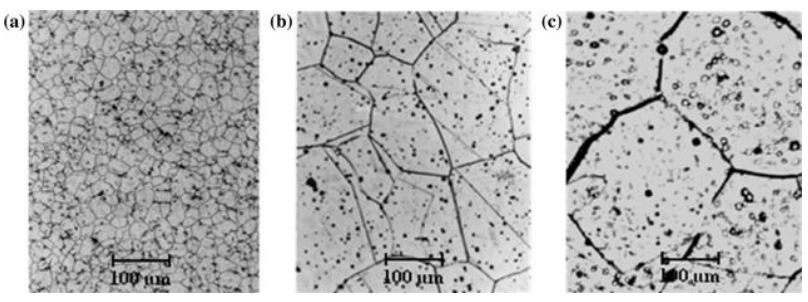

Fig. 1. Grain size in austenitic material [23].

The common signal processing methods, wavelet transform, s-transform, Hilbert-Huang transforms and split spectrum transform are used in ultrasonic detection. Each method will discussed in the next section and give overview the existing procedure

\subsection{Wavelet transform}

The wavelet transform (WT) is also a common method in ultrasonic signal analysis. It is similar to FT in mathematical model based on square integral and group theory. Raw signal will decomposed into different frequency scales [24]. This method is suitable when examining the signal in time-frequency resolution. It has been commonly used in industry applications, such as detection flaw, denoising, feature extraction and also for post-processing in classification [25][26]. Several parameters in wavelet need to consider such as the type of wavelet transform, mother wavelet, type of thresholding, threshold selection rule, decomposition level, and filter border treatment.

The wavelet is the latest generation compared to Fourier transform, the window size in wavelet transform is varies than the Fourier transform. Hence, timefrequency in wavelet transform is not compromised. Furthermore, low and high frequencies by long and short windows determined in time and frequency in wavelet transform. Wavelet transform can be categorized into continuous wavelet transform (CWT) and discrete wavelet transform (DWT). Khelil proposed a novel to recognize the wavelet representation is contaminated the structural noise or the flaw and used Morlet as mother wavelet [27]. In [28], Morlet wavelet and least mean squares (LMS) used as an adaptive filter. Four set of the simulated ultrasonic signal is obtained $-5 \mathrm{~dB},-10 \mathrm{~dB}$, $15 \mathrm{~dB}$ and $-20 \mathrm{~dB}$, and shown that the proposed method better than wavelet thresholding method at SNRs of less than $-5 \mathrm{~dB}$. This method is useful in the crack signal that masked with noise, the proposed scheme proves the reliability and efficiency for detecting and measuring crack. 
The discrete wavelet transform is widely used compared to continuous wavelet transform because the CWT method will have numerous coefficients and reduces the computational efficiency [29]. The researcher can encounter this problem toward DWT due to its execution speed and less memory requirement. In DWT, the raw signal will decompose into approximation (low frequency) and detail (high frequency) coefficient. After the first level decomposition, only the approximation decomposes to a higher level and the process is repeated until certain level [30. In [31], authors used DWT to analyze the ultrasonic signal of thick coarse-grained austenitic stainless steel. The proposed method uses Daubechies wavelet and decomposed signal up to 5 level and the improvement in SNR more than $13 \mathrm{~dB}$. Daubechies and Symlet wavelet based DWT is used in [32]. It inspects the ultrasonic signal by using high-order wavelet and 2 level of decomposition. The comparative study with Daubechies and Symlet performed between $4 \mathrm{~dB}$ until $36 \mathrm{~dB}$, it found that the higher order is greater in SNR but the processing time in $36 \mathrm{~dB}(1.096 \mathrm{~s})$ longer than $4 \mathrm{~dB}(0.605 \mathrm{~s})$. Abhishek et al. [33] have proposed his work on detection such as lack of fusion and slag of welding in two material which is carbonized steel and stainless steel. The proposed method uses Haar, dB1, dB2, dB3, biorthogonal and reverse bi-orthogonal, this method decomposed using DWT until 9 level. The energy calculated for each level of decomposition to characterized the defect. It has found Haar transform is the best method to characterize the flaw in the different material.

The integration in high frequencies it the main disadvantages in discrete wavelet transform. The researchers use WPT to avoid missing information in high frequencies. WPT can consider similar to DWT, the difference in WPT is both approximation and detail are decomposed into second-level approximation and details, and the process is repeated. The advantage of WPT is excellent frequency linearity and a higher ability of high-frequency identification. Therefore, wavelet packet transform is proposed in [34]. This scheme proposes a denoising procedure for flaw characterization in crater pipe and lack of fusion. The selection mother wavelet is shown the Daubechies function is more suitable than Coifee and Symlet. Daubechies function of order 8 and three level decomposition is selected in this method and give better result in SNR and the improvement as much as $11 \mathrm{~dB}$ in crater pipe and $6 \mathrm{~dB}$ in the lack of fusion. Shu-Fen et al. [35] introduce the ultrasonic detection based on WPT for seabed oil pipeline, in this scheme, Gaussian white noise has been taken in this method as a flaw noise in seabed pipeline which caused by system structure and ultrasound coupler impurity existence. Symlet 8 and decomposition level are three, the different threshold value and threshold function are selected for each experiment. The comparison shows the soft threshold value function is better for gliding property, while hard threshold value function is better for retain singularity and clearly reveal in flaw of seabed pipeline. Comparison with stationary, discrete wavelet packet de-noising has to be done in
[36], the comparison evaluated by means of SNR enhancement. The decomposition level is set by four level with different mother wavelet which is: Daubechies family of order $4(\mathrm{db} 4)$ and $6(\mathrm{db} 6)$, Symlet of order 6 (sym6), discrete Meyer wavelet (dmey) and Haar (haar). The best performance method is Meyer wavelet as mother wavelet in wavelet packet de-noising. The standard deviation and standard deviation with a mean value is most efficient threshold applied in this research. It enhanced in SNR up to $15 \mathrm{~dB}$ to $40 \mathrm{~dB}$.

\subsection{S-transform}

The s-transform is a combination of wavelet transform and short-time Fourier transform (STFT). It counters the problem that wavelet face in batch processing and noise sensitivity. It is based on a scalable localizing Gaussian window and providing a frequency dependent resolution [37]-[39]. S-transform provides multi-resolution and keep the absolute phase of each frequency. This processing method transfers the ultrasonic signal to twodimensional frequency domains.

In [40], the author described the time-frequency method, which is s-transform, and used Gabor transform with a frequency dependent window. They research the ultrasonic signal with the performance of s-transform. The linearity in s-transform is a good decision in timefrequency analysis of the ultrasonic signal for nondestructive testing. This method shows that the stransform provide better frequency resolution and time for detection of multiple echoes. Furthermore, in [41] the author used the modified S-transform (MST) and proposed a new method in thresholding modified stransform (TMST). The two parameters are very important in ultrasonic detection which is: arrival time and center frequency. the thresholding algorithm shows the computational time of TMST is almost similar to STFT and ST method. This proposed method can detect the close echo and give the best in detecting thin layer and detect delamination in the case of composite material. Haicao Cai et al. [42] studied in the thickwalled pipe and analyze the ultrasonic flaw echo signal by using modified s-transform domain singular value decomposition method. After applied s-transform, singular value decomposition used to calculate the signal singular entropy. The novel of this scheme improved by removing high and low frequency noise.

However s-transform method improved in a recent year, in [43] a novel method to improve detection in phased array ultrasonic for localizing with accuracy delamination defect. 3 method used in this process which is threshold modified s-transform algorithm (TMST), stransform Shannon energy (SSE) and threshold modified S-transform and Shannon energy (TMSSE). The combination of this method capable of resolving overlapping echoes. The accuracy localization is depending on the position of the defect, the estimation error is $3 \%$ for the defect away from front face and $13 \%$ for the defect closed to the front face. This method improved the quality of B-scan in the localization of delamination defects 


\subsection{Hilbert-Huang transform}

Hilbert-Huang transform is a commonly used in signal processing technique. Empirical mode decomposition is an adaptive method time-frequency analysis and pioneered by Huang. This method will extract the multicomponent signal into several IMF by using sifting process. Sifting indicates the process removing the low frequency and only remains the high frequency at last [44]. The signal of interest will be constructed by the sum of the selected IMF. In Hilbert spectral analysis, IMFs allow to calculate of instantaneous frequency and amplitude. Hilbert-Huang transforms known as combination of EMD with Hilbert transformv[45]. The conventional EMD method needs to clarify the specific IMF contains useful information or primarily noise. EMD is applicable for nonlinear and non-stationary signal, such as an ultrasonic signal. Two condition will satisfy as a function of IMF which is: first, in the raw data, the number of extrema and the number of zero crossing must be equal to each other or differ at most by one and second, at any point, the mean value of the envelope defined by the local maxima and the local minima is zero. The EMD method is based on the local characteristic time scale instead of the average time scale, so the instantaneous frequency has physical meaning. Moreover, it is a fully data-driven method.

In [46], few selected raw signal decomposed into a certain level of IMF. The energy is calculated every level of IMF and residue and reconstructed the sum of IMF from 3rd IMF until the last of IMF. The 3rd IMF as function as a threshold and enhanced the SNR up to $6 \mathrm{~dB}-8 \mathrm{~dB}$. Kazys et al. [47] improved the detection in high attenuation of the ultrasonic signal such as plastic pipe by using $5 \mathrm{MHz}$ transducers. The combination application is proposed using non-linear deconvolution and Hilbert-Huang transform. The first and second IMF show the information of the defect in the homogeneous one-layer plastic pipe. For improved the visualization of the defect, three-dimensional plot displayed in term of amplitude and the instantaneous frequency. This method suitable to investigate the defect in the polymer material. In [48], the method EMD is combined with singular spectrum analysis (SSA). The residue signal in IMF selected to be further tuned using SSA and windowing approach is used to utilizing the data. The proposed method showed the effectiveness in term of trend tracking and de-noising the ultrasonic signal. In [49], a series experiment was performed with three ultrasonic transducers and different bandwidth to investigate the rigid spherical flaw with $3 \mathrm{~mm}$ diameter. The best IMF and hypo-best IMF is selected to reconstruct the ultrasonic signal. The experiment validated the effectiveness of denoising and flaw identification. Li et al. [50] also proposed the selection method to reconstruct the signal, the raw ultrasonic signal decompose up to 6 IMFs by EMD and reconstruct the marginal spectrum of the different mode by the Hilbert transform. The noise from the ultrasonic signal can be removed after HHT and SNR can be improved.

However, EMD has some limitation in a decomposing ultrasonic signal the amplitude-frequency range are too close to each other [51]. To overcome this problem, EEMD is proposed to eliminate the mode mixing [51]. EEMD is proposed by decomposing with white noise with EMD. The calculation of IMF and mean value is used in [52] to optimizing the distribution of energy torque. The comparison of energy torque in EMD and EEMD is shown the EEMD approach is greatly improved. The basic EMD applied for IMF level and found in IMF2, IMF3 and IMF4 have no obvious increasing trend and cannot be used as a main and auxiliary feature. EEMD show the quantitative performance to diminish the mode mixing in EMD. Sharma et al. [23] proposed an effective reconstruction of the ultrasonic signal in coarse grain structure and the ability of B-scan is successfully demonstrated. EEMD and signal minimization algorithm is used to enhanced the SNR for the ultrasonic signal that obtained the artificial defect at a different depth. This method decomposed until 7 IMF and found at IMFs 3-5 clearly shoe information of back wall echo and selected this IMF that can provide the good signal to noise ratio. The enhancement the signal to noise ratio is around $15.9 \mathrm{~dB}$ and at least $7 \mathrm{~dB}$ extra compared to conventional selected IMF sum approach.

\subsection{Split spectrum processing}

Split spectrum processing (SSP) common method in recent year, the idea is splitting the signal into a number of frequency band. Frequency diversity based techniques appear in the dispersive material. The combined process of the splitting process is frequency sensitive due contribution filtering in each splitting frequency band. Two important process in SSP, namely, filter bank and the recombination technique [53], [54] and four parameters is very useful and sensitive which are number of filter, the filter bandwidth, the step frequency of filters and the position of the band pass (the first and last frequency center) [55]. A simulation study in [56] to detection delamination in composite material by using SSP. The process is associated with polarity threshold called (SSP-PT) and compared to expectationmaximization (EM) algorithm. Both methods can locate the defect area and SSP-PT is shown the output is better than EM in term of detection of precision of echo.

Another researcher tries combination SSP with Hough transform to enhance detection of defect [57]. It challenged in to detect the thickness of discontinuity is small than half of the ultrasound and then the diffracted and reflected wave will not be generated. Crack is presented in this study, the point of the sparse matrix from parabola and Hough transform can detect and help in decision making. This approach proved the reducing in required memory and processing time. However, this method is limited when the crack is close to surface because the tip-diffracted wave will disturbance with reflected wave from a surface. Haddad et al. [58] combined the EMD that capability for extracting the wave mode embedded in coherent or backscattering noise and the SSP capability of detecting multiple targets simultaneously. EMD is performed and selected the best 
IMF to be input in SSP. It decomposed into 3 level IMF and IMF2 is selected due to high energy than others IMF. The combination method confirmed more effective.

In [59], the SSP method will compare with some of the new extension and consider in this work with five variations for combination process which are polarity thresholding (PT), Scaled Polarity Thresholding (SPT), Minimization (MIN), Normalized Minimization (NORM) and Geometric Mean (GM). This method applied to the high dispersive material (cement) and low dispersive material (aluminum). It improved in SNR with the lowest number of band and achieves a very high value of the flaw-to-clutter Ratio (FCR). Benammar and
Drai [60] used SSP combined with matching pursuit signal decomposition (MPSD). SSP algorithm is used for signal to noise ratio enhancement and MPSD used to decompose backscattered signal into a linear expansion of chirplet echoes. Three type of delamination defect inserted in this study which is Teflon, air, and nylon is investigated with two different transducer frequency $2.25 \mathrm{MHz}$ and $5 \mathrm{MHz}$, respectively. Deconvolution, SSPPT and the SSP-MPSD algorithm used to determine defect position and resolution. It shows the average error in SSP-MPSD is low than another method. Table 1 summarizes the aforementioned signal processing based on ultrasonic signal detection in material.

Table 1. Summary of signal processing in ultrasonic detection techniques

\begin{tabular}{|c|c|c|c|c|c|c|}
\hline Category & Reference & SP method & Idea & Application & Flaw Detection & $\begin{array}{l}\text { Advantages \& } \\
\text { disadvantages }\end{array}$ \\
\hline \multirow[t]{7}{*}{$\begin{array}{l}\text { Wavelet } \\
\text { transform }\end{array}$} & $\begin{array}{l}\text { Song Shou- } \\
\text { peng [61] }\end{array}$ & WT & $\begin{array}{l}\text { Wavelet treated } \\
\text { as band pass } \\
\text { filter }\end{array}$ & $\begin{array}{l}\text { Offshore } \\
\text { pipeline } \\
\text { spacemen }\end{array}$ & $\begin{array}{l}\text { Man-made } \\
\text { crack } \\
\text { fabricated }\end{array}$ & $\begin{array}{l}\text { Time saving } \\
\text { Effective removing } \\
\text { white noise }\end{array}$ \\
\hline & $\begin{array}{l}\text { Sharma } \\
{[31]}\end{array}$ & DWT & $\begin{array}{l}\text { Reducing noise } \\
\text { and using } \\
\text { Daubechies } \\
\text { (db8) }\end{array}$ & $\begin{array}{l}\text { Austenitic } \\
\text { stainless steel }\end{array}$ & $\begin{array}{l}\text { Coarse-grained } \\
\text { flaws } \\
\text { machined at } \\
\text { different } \\
\text { depths } \\
\end{array}$ & $\begin{array}{l}\text { Fast and attractive for } \\
\text { online implementation }\end{array}$ \\
\hline & $\begin{array}{l}\text { Angam } \\
\text { Praveen } \\
{[32]}\end{array}$ & DWT & $\begin{array}{l}\text { De-noising with } \\
\text { high order } \\
\text { wavelet } \\
\text { Comparison } \\
\text { Daubechies and } \\
\text { symlet families }\end{array}$ & $\begin{array}{l}\text { Austenitic } \\
\text { Stainless Steel } \\
\text { welds }\end{array}$ & $\begin{array}{l}\text { Coarse grains } \\
\text { structure }\end{array}$ & $\begin{array}{l}\text { Higher order wavelets } \\
\text { yield greater SNR } \\
\text { values }\end{array}$ \\
\hline & $\begin{array}{l}\text { Abhishek } \\
\text { Kumar } \\
\text { Singh [33] }\end{array}$ & DWT & $\begin{array}{l}\text { Energy is } \\
\text { calculated from } \\
\text { DWT } \\
\text { approximation } \\
\text { coefficient }\end{array}$ & $\begin{array}{l}\text { Carbonized } \\
\text { steel and } \\
\text { stainless steel } \\
\text { material }\end{array}$ & $\begin{array}{l}\text { Lack of fusion } \\
\text { and slag of } \\
\text { welding }\end{array}$ & $\begin{array}{l}\text { Haar the best suited of } \\
\text { mother wavelet for } \\
\text { different material }\end{array}$ \\
\hline & $\begin{array}{l}\text { Fairouz } \\
\text { Bettayeb } \\
{[34]}\end{array}$ & WPT & $\begin{array}{l}\text { Comparison } \\
\text { coiflet, symlet, } \\
\text { debauchees }\end{array}$ & Weldments & $\begin{array}{l}\text { Crater pipe } \\
\text { flaw } \\
\text { Lack of fusion }\end{array}$ & $\begin{array}{l}\text { SNR enhancements } \\
(6 \mathrm{~dB}-11 \mathrm{~dB}) \\
\text { Improvement } \\
\text { computing time and } \\
\text { memory space } \\
\text { Coiflet and Symlet no } \\
\text { produced any filtering }\end{array}$ \\
\hline & $\begin{array}{l}\text { Vaclav } \\
\text { Matz [36] }\end{array}$ & WT & $\begin{array}{l}\text { Comparative } \\
\text { study based on } \\
\text { SWT, DWT, } \\
\text { and WPT }\end{array}$ & $\begin{array}{l}\text { Simulated } \\
\text { ultrasonic } \\
\text { signal with } \\
\text { different size } \\
\text { of fault echo }\end{array}$ & $\begin{array}{l}\text { coarse-grained } \\
\text { structure }\end{array}$ & $\begin{array}{l}\text { WPT de-noising was } \\
\text { the best performing, } \\
\text { SNR }(15-40 \mathrm{~dB}) \\
\text { Meyer the most } \\
\text { effective mother } \\
\text { wavelet }\end{array}$ \\
\hline & $\begin{array}{l}\text { Shu-Fen Qi } \\
{[35]}\end{array}$ & WPT & $\begin{array}{l}\text { Different } \\
\text { threshold values } \\
\text { and threshold } \\
\text { value functions } \\
\text { are compared } \\
\end{array}$ & $\begin{array}{l}\text { Seabed oil } \\
\text { pipeline }\end{array}$ & - & $\begin{array}{l}\text { Improve the ability of } \\
\text { seabed oil pipeline } \\
\text { ultrasonic testing }\end{array}$ \\
\hline \multirow[t]{3}{*}{$\begin{array}{l}\text { s- } \\
\text { transform }\end{array}$} & $\begin{array}{l}\text { Haichao } \\
{[42]}\end{array}$ & s-transform & $\begin{array}{l}\text { Modified s- } \\
\text { transform and } \\
\text { singular value } \\
\text { decomposition } \\
\text { denoising } \\
\text { algorithm } \\
\text { model } \\
\end{array}$ & $\begin{array}{l}\text { Thick walled } \\
\text { pipe }\end{array}$ & Small flaw & $\begin{array}{l}\text { Ability to remove low- } \\
\text { frequency noise } \\
\text { Improve SNR }\end{array}$ \\
\hline & Malik [40] & s-transform & $\begin{array}{l}\text { Detection of } \\
\text { multiple echoes }\end{array}$ & $\begin{array}{l}\text { Microstructure } \\
\text { grain noise }\end{array}$ & Flaw echo & $\begin{array}{l}\text { Better time and } \\
\text { frequency resolution }\end{array}$ \\
\hline & Bennamar & Modified s- & Improve & Composite & Flat bottom & Ability to detect close \\
\hline
\end{tabular}




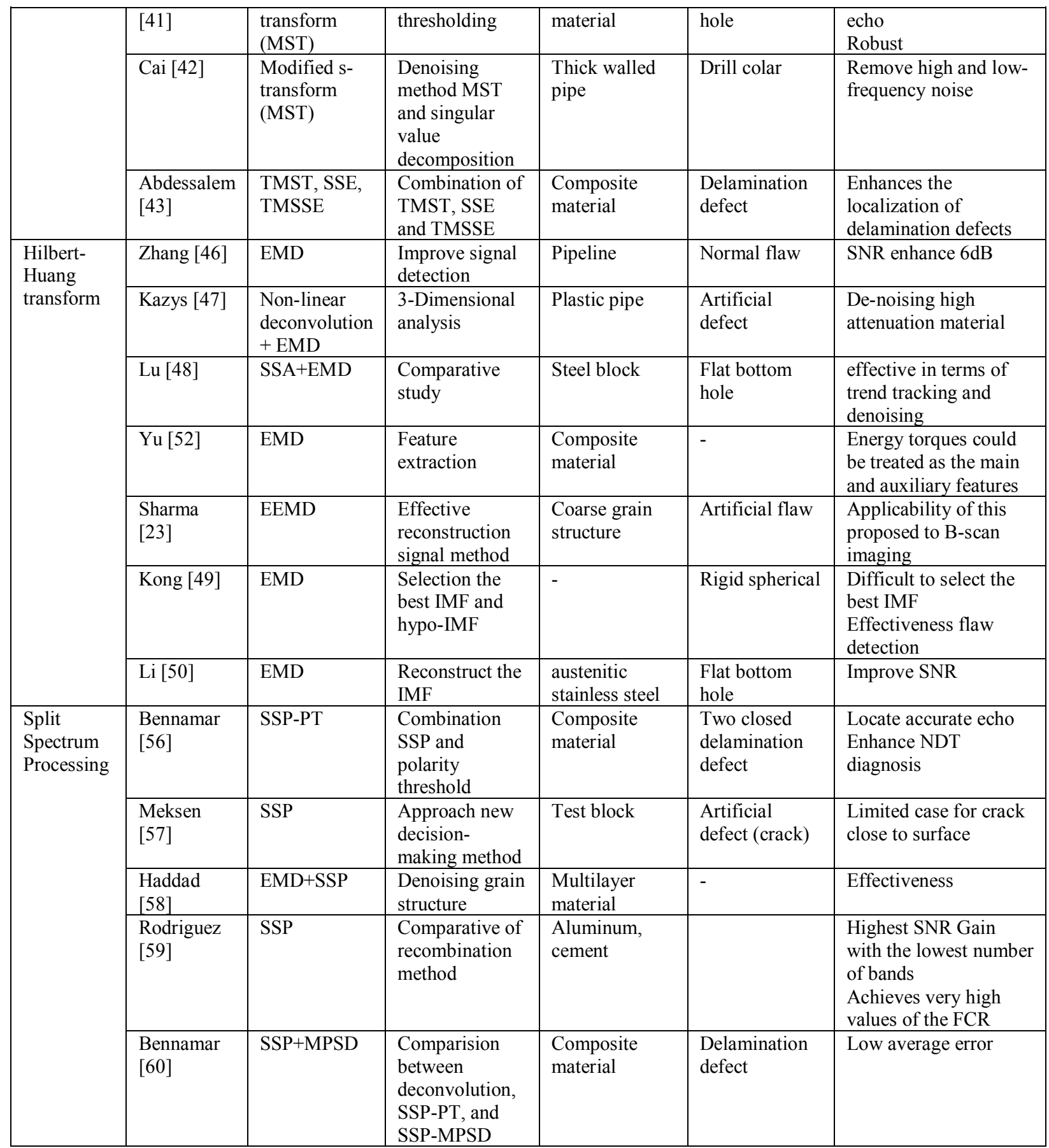

\section{Signal processing based ultrasonic detection techniques with intelligent classifier}

Until now, in ultrasonic signal processing techniques, the desired feature extraction from the input signal and compared to a threshold value. It difficult task to determine the threshold value, if the threshold value set high, the ultrasonic signal information will lose and while threshold value set low, the signal will mask with a noisy signal. To overcome this issue, the artificial intelligent classifier has been combined with signal processing in ultrasonic signal techniques. The commonly artificial intelligent used in signal processing are artificial neural network (ANN), support vector machine (SVM),

Jingwen et al. [62] presented a new technique for ultrasonic detection based on wavelet for feature extraction and artificial neural network (ANN) as an intelligent classifier. On the basis of the experimental results, it was verified that proposed scheme was very effective in oil pipeline corrosion. The classifier in this method divided into four group which are no corrosion, mild corrosion, moderate corrosion, and serious corrosion. In [63], the researchers used intelligent classifier and simulated lamb wave to extract a feature from simulation data and reduce the number of specimens by using a neural network. Morlet wavelet is chosen in continuous wavelet as mother wavelet for denoising process. Extracting robust and crack- 
sensitive feature from time domain is important for health monitoring. Morteza et al. [64] propose a novel method that can localize and severity in hydrocarbon pipeline. Multi-layer perceptron neural network (MLPNN) used with some various feature extraction which are statistical techniques, wavelet transform and a fusion of both methods. It reveals more accurate in MLPNN yield by used the fusion based feature extraction method. It shows the fusion method in correct classification rate (CCR) up to $91.8919 \%$ and better than other. The wavelet transforms also used for denoising [65], the deep convolutional neural network used to learn the coefficient from wavelet processing. It also proposed the good method in signal classification by using a linear support vector machine (SVM) at the top layer. This research shows that the algorithm is effective in classifying defect in the ultrasonic signal. Sambath et al. [66], Daubechies mother wavelet and ANN classifier used for detection and classify the flaw. 8 features giving the best discrimination between material defect for input vector in ANN. Two hidden layers proposed in ANN method, with 8 nodes and 25 nodes, respectively. The output node set by 3 for output classifier. In this proposed method, it shows the classification rate is $94 \%$ and high reliable and precise for online monitoring.

Yang [67] proposed ANN to train the classifier of flaw detection by extracting a feature from empirical mode decomposition. Seven IMF decomposed from the ultrasonic signal and selected IMF1 until IMF5 as input vector of ANN. It derives 10 numbers of a feature in the time domain and four number of a feature in the frequency domain. Three classification method introduced which is a combination of EMD-PCA, EMD-RSAR, and DWT-PCA. It found EMD-RSAR could achieve high classification accuracy and training efficiency. In [68], a comparative novel technique is proposed based on support vector machine (SVM) classifier with and without split spectrum analysis signal processing. From the confusion matrix for predicted flaw, the accuracy without SSP is $93.6 \%$ and with SSP the accuracy $97.8 \%$. Table 2 summaries the signal processing in ultrasonic detection with intelligent classifiers

Table 2. Summary of intelligent classifier with signal processing method

\begin{tabular}{|c|c|c|c|c|c|c|}
\hline Category & Reference & $\begin{array}{l}\text { SP } \\
\text { method }\end{array}$ & $\begin{array}{l}\text { Intelligent } \\
\text { classifier }\end{array}$ & Idea & $\begin{array}{l}\text { Application / } \\
\text { Flaw Detection }\end{array}$ & $\begin{array}{l}\text { Advantages \& } \\
\text { disadvantages }\end{array}$ \\
\hline \multirow[t]{5}{*}{$\begin{array}{l}\text { Wavelet } \\
\text { transform }\end{array}$} & $\begin{array}{l}\text { Jingwen } \\
{[62]}\end{array}$ & WT & WNN & $\begin{array}{l}\text { Multi-sensor with } 3 \\
\text { group of Ultrasonic } \\
\text { and flux leakage }\end{array}$ & $\begin{array}{l}\text { Detection the } \\
\text { corrosion } \\
\text { degree in } \\
\text { pipeline }\end{array}$ & $\begin{array}{l}\text { Feasible and effective } \\
\text { Faster convergence rate }\end{array}$ \\
\hline & Liu [63] & CWT & ANN & $\begin{array}{l}\text { Approach to } \\
\text { detecting and } \\
\text { characterizing }\end{array}$ & $\begin{array}{l}\text { Crack in } \\
\text { metallic plate }\end{array}$ & $\begin{array}{l}\text { Effectively detect } \\
\text { cracks }\end{array}$ \\
\hline & $\begin{array}{l}\text { Zadkaram } \\
\text { i [64] }\end{array}$ & WT & MLPNN & $\begin{array}{l}\text { Comparative feature } \\
\text { extraction method in } \\
\text { MLPNN }\end{array}$ & $\begin{array}{l}\text { Pipeline } \\
\text { leakage }\end{array}$ & $\begin{array}{l}\text { Fusion method more } \\
\text { accurate results }\end{array}$ \\
\hline & Meng [65] & WT & $\begin{array}{l}\text { Deep } \\
\text { convolutional } \\
\text { neural } \\
\text { network }+ \\
\text { SVM }\end{array}$ & $\begin{array}{l}\text { Classification the } \\
\text { defect }\end{array}$ & $\begin{array}{l}\text { Void and } \\
\text { delamination }\end{array}$ & $\begin{array}{l}\text { Effective in classifying } \\
\text { the defect signals }\end{array}$ \\
\hline & $\begin{array}{l}\text { Sambath } \\
{[66]}\end{array}$ & DWT & ANN & $\begin{array}{l}\text { Classification the } \\
\text { defect }\end{array}$ & $\begin{array}{l}\text { Porosity, lack } \\
\text { of fusion, } \\
\text { tungsten } \\
\text { inclusion and } \\
\text { no defect }\end{array}$ & $\begin{array}{l}\text { High classification rate } \\
\text { Reliable and precise }\end{array}$ \\
\hline $\begin{array}{l}\text { Split } \\
\text { spectrum } \\
\text { processing }\end{array}$ & $\begin{array}{l}\text { Kushal } \\
{[68]}\end{array}$ & SSP & SVM & $\begin{array}{l}\text { Comparative study } \\
\text { with and without SSP }\end{array}$ & Steel block & $\begin{array}{l}\text { More accuracy by using } \\
\text { SSP+SVM }\end{array}$ \\
\hline $\begin{array}{l}\text { Hilbert- } \\
\text { Huang } \\
\text { transform }\end{array}$ & Yang [67] & EMD & ANN & $\begin{array}{l}\text { Classification method } \\
\text { combine with rough } \\
\text { set attribute reduction }\end{array}$ & $\begin{array}{l}\text { Carbon fiber } \\
\text { reinforced } \\
\text { polymer } \\
\text { (CFRP) with } \\
\text { delamination, } \\
\text { debonding and } \\
\text { void }\end{array}$ & $\begin{array}{l}\text { High classification } \\
\text { accuracy and training } \\
\text { efficiency }\end{array}$ \\
\hline
\end{tabular}


Table 3. Comparison between different feature extraction technique

\begin{tabular}{|l|l|l|l|}
\hline No & SP method & Advantages & Disadvantages \\
\hline 1 & Wavelet & $\begin{array}{l}\text { Good in time and frequency. } \\
\text { High computational seed }\end{array}$ & $\begin{array}{l}\text { Batch processing } \\
\text { Mother wavelet selection }\end{array}$ \\
\hline 2 & S-transform & $\begin{array}{l}\text { Efficient and accurate } \\
\text { Ability to transform time domain to } \\
\text { 2-dimensional frequency domain }\end{array}$ & $\begin{array}{l}\text { It does not perform well in transient and } \\
\text { harmonic } \\
\text { Not work properly in real environment }\end{array}$ \\
\hline 3 & Hilbert-Huang transform & $\begin{array}{l}\text { Ability in distorted signal feature } \\
\text { extraction }\end{array}$ & $\begin{array}{l}\text { Loss of frequency component in low energy } \\
\text { contents }\end{array}$ \\
\hline 4 & Split spectrum processing & $\begin{array}{l}\text { Ability to generate time resolution at } \\
\text { high frequencies } \\
\text { Very flexible }\end{array}$ & Coarse time resolution at low frequencies \\
\hline
\end{tabular}

\section{Conclusion}

This paper explains the review on ultrasonic signal processing techniques used in the pipeline system. At first part, type of defect occur in pipeline was overview. The existing signal processing technique was study for de-noising techniques to enhance the signalto-noise ratio. It very important process to reduce noise that masked flaw signal. Signal processing with an intelligent classifier achieves the high accuracy, faster detection and good in the classification of the defect, table 6 shows the advantages and disadvantages of feature extraction method for each signal processing method. In the pipeline, a fast decision needs to be done by an engineer before severe damage occur in the pipeline and can classify the types of defect and the severity of the defect. Thus, in the real-time applications, signal processing is suitable and great potential.

\section{Acknowledgement}

The authors would like to extend their greatest gratitude to the Institute of Noise and Vibration UTM for funding the study under the Higher Institution Centre of Excellence (HICoE) Grant Scheme (R.K130000.7809.4J225, R.K130000.7843.4J226, R.K130000.7843.4J227). Additional funding for this research also comes from the UTM Research University Grant (Q.K130000.2543.11H36).

\section{References}

1. Z. Liu and Y. Kleiner, "State of the art review of inspection technologies for condition assessment of water pipes," Meas. J. Int. Meas. Confed., vol. 46, no. 1, pp. 1-15, 2013.

2. Y. Javadi, H. S. Pirzaman, M. H. Raeisi, and M. A. Najafabadi, "Ultrasonic inspection of a welded stainless steel pipe to evaluate residual stresses through thickness," Mater. Des., vol. 49, pp. 591601, 2013.

3. M. Kubinyi, O. Kreibich, J. Neuzil, and R. Smid, "Novel S-transform information fusion for filtering ultrasonic pulse-echo signals," no. 1, pp. 290-295, 2011.
4. I. Bosch and L. Vergara, "Normalized splitspectrum: A detection approach," Ultrasonics, vol. 48, no. 1, pp. 56-65, 2008.

5. M. R. Dann and C. Dann, "Automated matching of pipeline corrosion features from in-line inspection data," Reliab. Eng. Syst. Saf., vol. 162, no. January, pp. 40-50, 2017.

6. L. Zhang et al., "Effect of the cathodic current density on the sub-surface concentration of hydrogen in X80 pipeline steels under cathodic protection," Int. J. Hydrogen Energy, vol. 42, no. 5, pp. 3389-3398, 2016.

7. M. A. Mohtadi-Bonab, M. Eskandari, K. M. M. Rahman, R. Ouellet, and J. A. Szpunar, "An extensive study of hydrogen-induced cracking susceptibility in an API X60 sour service pipeline steel," Int. J. Hydrogen Energy, vol. 41, no. 7, pp. 4185-4197, 2016.

8. Z. Y. Liu, X. Z. Wang, C. W. Du, J. K. Li, and X. G. Li, "Effect of hydrogen-induced plasticity on the stress corrosion cracking of X70 pipeline steel in simulated soil environments," Mater. Sci. Eng. A, vol. 658, pp. 348-354, 2016.

9. C. Zhou et al., "Sulphide stress cracking behaviour of the dissimilar metal welded joint of X60 pipeline steel and Inconel 625 alloy," Corros. Sci., vol. 110, pp. 242-252, 2016.

10. S. Ranade, M. Forsyth, and M. Y. J. Tan, "In situ measurement of pipeline coating integrity and corrosion resistance losses under simulated mechanical strains and cathodic protection," Prog. Org. Coatings, vol. 101, pp. 111-121, 2016.

11. I. M. Dmytrakh, R. L. Leshchak, and A. M. Syrotyuk, "Effect of hydrogen concentration on fatigue crack growth behaviour in pipeline steel," Int. J. Hydrogen Energy, vol. 0, no. 9, pp. 2-9, 2014.

12. X. Shi, W. Yan, W. Wang, L. Zhao, Y. Shan, and K. Yang, "Effect of Microstructure on Hydrogen Induced Cracking Behavior of a High Deformability Pipeline Steel," J. Iron Steel Res. Int., vol. 22, no. 10, pp. 937-942, 2015.

13. Z. Fan, X. Hu, J. Liu, H. Li, and J. Fu, "Stress corrosion cracking of L360NS pipeline steel in sulfur environment," Petroleum, pp. 6-12, 2017. 
14. K. G. Solheim and J. K. Solberg, "Hydrogen induced stress cracking in supermartensitic stainless steels - Stress threshold for coarse grained HAZ," Eng. Fail. Anal., vol. 32, no. 4035, pp. 348-359, 2013.

15. F. Sun, S. Ren, Z. Li, Z. Liu, X. Li, and C. Du, "Comparative study on the stress corrosion cracking of X70 pipeline steel in simulated shallow and deep sea environments," Mater. Sci. Eng. A, vol. 685, no. October 2016, pp. 145-153, 2017.

16. Z. Ignaszak, P. Popielarski, J. Hajkowski, and J. B. Prunier, "Problem of Acceptability of Internal Porosity in Semi-Finished Cast Product as New Trend - 'Tolerance of Damage' Present in Modern Design Office," Diffus. Solids Liq. Vii, vol. 326328, pp. 612-619, 2012.

17. R. E. Vieira, M. Parsi, P. Zahedi, B. S. McLaury, and S. A. Shirazi, "Ultrasonic measurements of sand particle erosion under upward multiphase annular flow conditions in a vertical-horizontal bend," Int. J. Multiph. Flow, vol. 93, pp. 48-62, 2017.

18. C. B. Solnordal, C. Y. Wong, and J. Boulanger, "An experimental and numerical analysis of erosion caused by sand pneumatically conveyed through a standard pipe elbow," Wear, vol. 336337, pp. 43-57, 2015.

19. E. Mazzocchi, A. J. Pachoud, M. Farhat, F. E. Hachem, G. De Cesare, and A. J. Schleiss, "Signal analysis of an actively generated cavitation bubble in pressurized pipes for detection of wall stiffness drops," J. Fluids Struct., vol. 65, pp. 60-75, 2016.

20. B. Wu, Y. Huang, and S. Krishnaswamy, "A Bayesian approach for sparse flaw detection from noisy signals for ultrasonic NDT," NDT E Int., vol. 85, no. February 2016, pp. 76-85, 2017.

21. J. Chen, Y. Shi, and S. Shi, "Noise analysis of digital ultrasonic nondestructive evaluation system," Int. J. Press. Vessel. Pip., vol. 76, no. 9, pp. 619-630, 1999.

22. J. Chen, Y. Shi, and S. Shi, "Noise analysis of digital ultrasonic system and elimination of pulse noise," Int. J. Press. Vessel. Pip., vol. 75, pp. 887890, 1998.

23. G. K. Sharma, A. Kumar, T. Jayakumar, B. Purnachandra Rao, and N. Mariyappa, "Ensemble Empirical Mode Decomposition based methodology for ultrasonic testing of coarse grain austenitic stainless steels," Ultrasonics, vol. 57, pp. 167-178, 2015.

24. C. Liner, "An overview of wavelet transform concepts and applications," Univ. Houst., pp. 117, 2010.

25. Y. Wang, "Wavelet Transform Based Feature Extraction for Ultrasonic Flaw Signal Classification," J. Comput., vol. 9, no. 3, pp. 725$732,2014$.
26. W. K. Ngui, M. S. Leong, L. M. Hee, and A. M. Abdelrhman, "Wavelet Analysis: Mother Wavelet Selection Methods," Appl. Mech. Mater., vol. 393, pp. 953-958, 2013.

27. M. Khelil, J.-H. Thomas, L. Simon, R. El Guerjouma, and M. Boudraa, "Characterization of Structural Noise Patterns and Echo Separation in the Time-Frequency Plane for Austenitic Stainless Steels," J. Nondestruct. Eval., vol. 36, no. 2, p. 31, 2017.

28. H. Chen, M. J. Zuo, X. Wang, and M. R. Hoseini, "An adaptive Morlet wavelet filter for time-offlight estimation in ultrasonic damage assessment," Meas. J. Int. Meas. Confed., vol. 43, no. 4, pp. 570-585, 2010.

29. Y. Chen and M. Road, "Testing of Welding Flaws," pp. 25-28, 2008.

30. V. Matz, M. Kreidl, and R. Šmíd, "Signal-to-Noise Ratio Improvement based on the Discrete Wavelet Transform in Ultrasonic Defectoscopy," Acta Polytech., vol. 44, no. 4, pp. 61-66, 2004.

31. G. K. Sharma, S. Bhagi, S. Thirunavukkarasu, and B. P. Rao, "Wavelet transform-based approach for processing ultrasonic B-scan images," Insight Non-Destructive Test. Cond. Monit., vol. 59, no. 2, pp. 93-99, 2017.

32. A. Praveen, K. Vijayarekha, S. T. Abraham, and B. Venkatraman, "Signal quality enhancement using higher order wavelets for ultrasonic TOFD signals from austenitic stainless steel welds," Ultrasonics, vol. 53, no. 7, pp. 1288-1292, 2013.

33. K. S. Abhishek kumar singh, Gurav pratap singh, "Weld Flaw Characterization Through Mathematical Modeling From Ultrasonic Signal," 2015.

34. F. Bettayeb, S. Haciane, and S. Aoudia, "Improving the time resolution and signal noise ratio of ultrasonic testing of welds by the wavelet packet," NDT E Int., vol. 38, no. 6, pp. 478-484, 2005.

35. S. F. Qi, C. Zhao, and Y. Yang, "Research on ultrasonic detection of seabed oil pipeline based on wavelet packet de-noising," Proc. - 5th Int. Conf. Wirel. Commun. Netw. Mob. Comput. WiCOM 2009, pp. 4-7, 2009.

36. V. Matz, R. Smid, S. Starman, and M. Kreidl, "Signal-to-noise ratio enhancement based on wavelet filtering in ultrasonic testing," Ultrasonics, vol. 49, no. 8, pp. 752-759, 2009.

37. S. Ventosa, C. Simon, M. Schimmel, J. J. Danobeitia, and A. Manuel, "The S-transform from a wavelet point of view," IEEE Trans. Signal Process., vol. 56, no. 7 I, pp. 2771-2780, 2008.

38. P. Dash, B. K. Panigrahi, and G. Panda, "Power quality analysis using s-transform," IEEE Trans. Power Deliv., vol. 18, no. 2, pp. 406-411, 2003. 
39. R. G. Stockwell, L. Mansinha, and R. P. Lowe, "Localization of the complex spectrum: The S transform," IEEE Trans. Signal Process., vol. 44, no. 4, pp. 998-1001, 1996.

40. M. A. Malik, "s-transform applied to ultrasonic nondestructive testing," IEEE Int. Ultrason. Symp. Proc., no. 3, pp. 184-187, 2008.

41. A. Benammar, R. Drai, and A. Guessoum, "Ultrasonic flaw detection using threshold modified S-transform," Ultrasonics, vol. 54, no. 2, pp. 676-683, 2014.

42. H. Cai, C. Xu, S. Zhou, H. Yan, and L. Yang, "Study on the Thick-Walled Pipe Ultrasonic Signal Enhancement of Modified S-Transform and Singular Value Decomposition," vol. 2015, 2015.

43. B. Abdessalem, K. Ahmed, and D. Redouane, "Signal Quality Improvement Using a New TMSSE Algorithm: Application in Delamination Detection in Composite Materials," $J$. Nondestruct. Eval., vol. 36, no. 1, p. 16, 2017.

44. M. Manjula and A. V. R. S. Sarma, "Comparison of empirical mode decomposition and wavelet based classification of power quality events," Energy Procedia, vol. 14, pp. 1156-1162, 2012.

45. N. Huang et al., "The empirical mode decomposition and the Hilbert spectrum for nonlinear and non-stationary time series analysis," Proc. R. Soc. A Math. Phys. Eng. Sci., vol. 454, no. 1971, pp. 995, 903, 1998.

46. Q. Zhang, P. W. Que, Q. K. Liu, T. L. Chen, and T. Han, "Application of empirical mode decomposition to ultrasonic signal," Proc. - IEEE Ultrason. Symp., vol. 3, no. 1, pp. 1789-1792, 2005.

47. R. Kažys, O. Tumšys, and D. Pagodinas, "Ultrasonic detection of defects in strongly attenuating structures using the Hilbert-Huang transform," NDT E Int., vol. 41, no. 6, pp. 457466, 2008.

48. Y. Lu and J. Saniie, "A Comparative Study of Singular Spectrum Analysis and Empirical Mode Decomposition for Ultrasonic NDE," no. 1, pp. 14, 2016.

49. T. Kong, C. Xu, and S. Zhou, "A time-frequency method for ultrasonic flaw inspection based on HHT," Proc. - 2010 3rd Int. Congr. Image Signal Process. CISP 2010, vol. 8, no. 1, pp. 3988-3991, 2010.

50. Q. F. Li, Y. Wang, and L. Y. Xi, "Research on Ultrasonic Testing of Coarse-Grain Materials with Hilbert-Huang Transform," Adv. Mater. Res., vol. 820, pp. 97-101, 2013.

51. S. Wu, "Solution for Mode Mixing Phenomenon of the Empirical Mode Decomposition," 3rd Int. Conforence Adv. Comput. Theory Eng., pp. 500504, 2010.
52. J. M. Yu and Z. Zhang, "Research on Feature Extraction for Ultrasonic Echo Signal Based on EEMD Approach," Appl. Mech. Mater., vol. 321324, pp. 1311-1316, 2013.

53. N. M. B. Qi Tian, Xing Li, "Multiple Target Detection Using Split Spectrum Processing and Group Delay Moving Entropy.” 1995.

54. P. M. Shankar, V. L. Newhouse, P. Karpur, and J. L. Rose, "Split-Spectrum Processing: Analysis of Polarity Thresholding Algorithm for Improvement of Signal-to-Noise Ratio and Detectability in Ultrasonic Signals," IEEE Trans. Ultrason. Ferroelectr. Freq. Control, vol. 36, no. 1, pp. 101108, 1989.

55. P. Karpur, P. M. Shankar, J. L. Rose, and V. L. Newhouse, "Split spectrum processing: Determination of the available bandwidth for spectral splitting," Ultrasonics, vol. 26, no. 4, pp. 204-209, Jul. 1988.

56. A. Benammar, R. Drai, and A. Guessoum, "Detection of delamination defects in CFRP materials using ultrasonic signal processing," Ultrasonics, vol. 48, no. 8, pp. 731-738, 2008.

57. T. Meksen, B. Boudraa, and M. Boudraa, "A method to improve and automate flat defect detection during ultrasonic inspection," Int. J. Adapt. Control Signal Process., vol. 22, pp. 375383, 2012.

58. S. Haddad, M. Grimes, T. Benkedidah, and A. Bouhadjera, "Ultrasonic Signal Processing Based on the Combined Use of Empirical Mode Decomposition and Split Spectrum Processing Using the Prism Technique," Nondestruct. Test. Mater. Struct., vol. 6, pp. 143-148, 2012.

59. A. Rodríguez, R. Miralles, I. Bosch, and L. Vergara, "New analysis and extensions of splitspectrum processing algorithms," NDT E Int., vol. 45, no. 1, pp. 141-147, 2012.

60. B. Abdessalem and D. Redouane, "Ultrasonic Flaw Detection in Composite Materials Using SSP-MPSD Algorithm," vol. 9, no. 5, pp. 17531761, 2014.

61. S. Song and P. Que, "Wavelet based noise suppression technique and its application to ultrasonic flaw detection.," Ultrasonics, vol. 44, pp. 188-93, 2006.

62. T. Jingwen, G. Meijuan, Z. Hao, and L. Kai, "Corrosion detection system for oil pipelines based on multi-sensor data fusion by wavelet neural network," 2007 IEEE Int. Conf. Control Autom. ICCA, vol. 0, pp. 2958-2963, 2008.

63. S. Liu, C. Du, J. Mou, L. Martua, J. Zhang, and F. L. Lewis, "Diagnosis of structural cracks using wavelet transform and neural networks," NDT E Int., vol. 54, pp. 9-18, 2013.

64. M. Zadkarami, M. Shahbazian, and K. Salahshoor, "Pipeline leakage detection and isolation: An integrated approach of statistical and wavelet 
feature extraction with multi-layer perceptron neural network (MLPNN)," J. Loss Prev. Process Ind., vol. 43, pp. 479-487, 2016.

65. M. Meng, Y. J. Chua, E. Wouterson, and C. P. K. Ong, "Ultrasonic signal classification and imaging system for composite materials via deep convolutional neural networks," Neurocomputing, vol. 0, pp. 1-8, 2017.

66. S. Sambath, P. Nagaraj, and N. Selvakumar, "Automatic defect classification in ultrasonic NDT using artificial intelligence," J. Nondestruct. Eval., vol. 30, no. 1, pp. 20-28, 2011.

67. P. Yang and Q. Yang, "Empirical Mode Decomposition and Rough Set Attribute Reduction for Ultrasonic Flaw Signal Classification," Int. J. Comput. Intell. Syst., pp. 1-12, 2014.

68. K. Virupakshappa and E. Oruklu, "Ultrasonic flaw detection using Support Vector Machine classification," 2015 IEEE Int. Ultrason. Symp., pp. 1-4, 2015. 